\title{
Numerical and Analytical Investigation on the Effect of Dynamic Characteristics of Metal Expansion Bellows
}

\author{
A. B. Kadam, S. P. Gadewar, S.H.Gawande \\ Department of Mechanical Engineering, M. E. S. College of Engineering ,Pune, S.P.Pune University, India
}

\begin{abstract}
Metal bellows are elastic vessels that can be compressed when pressure is applied to outside of the vessel, or extended under vacuum. This is the mechanical device with wide range of applications due to its characteristic nature in absorbing energy and displacement in the structure. Structures are like bridges, industrial actuators, piping systems etc. These are widely use in aeronautical domains and medical applications. This paper is based on the objective as to investigate the numerical and analytical approach on the effect of dynamic characteristics of metal expansion bellows. $U$-shaped bellows having 6 and 7 convolutions are taken as specimen for analysis to find axial natural frequencies. Analysis is carried out by using MATLAB software for performing numerical analysis based on existing mathematical model proposed in a research paper [1] and ANSYS15 is used for performing modal analysis. Considering different end conditions for analysis, the comparative results of numerical (MATLAB) and analytical (FEA) analysis shows a very close match.
\end{abstract}

Keywords: Natural Frequency, Metal Expansion Bellows, Deformation, Modal Analysis, MATLAB, ANSYS15

\section{Introduction}

In process industries shell and tube heat exchangers are widely used due to large ratio of heat transfer area to volume and weight. Heat transfer between fluid flowing inside and outside is due to the tube of the heat exchanger. Tube is the basic component of heat exchanger enclosed with shell. Shell and tube heat exchangers are able to operate with wide temperature, vibrations, internal pressure and aggressive corrosion environment. Due to this the shell is stressed under axial pressure, thermal load and vibrations. These extreme working conditions cause the expansion and contraction of shell. Increasing the expansion and contraction leads the chances of shell failure.

An expansion joint is used in STHE in order to counterbalance the deformation. Generally metal bellows are used as an expansion joint in STHE. Metal bellows have large area of application in air conditioning equipment, industrial plants, hose pipes, vacuum systems, aerospace equipment etc. Selection of proper material, design and manufacturing methods are used to achieve highly flexible and high strength bellows. Bellows having capability to deal with combined effect of vibrations, thermal expansion, angular, radial, and axial displacements of the system. To resist the pressure and accept the deflections bellows must be designed circumferentially strong and longitudinally flexible respectively.

Generally forming, bulging and drawing process are used to manufacture the metal bellows. Stainless steel is commonly used material but in some special applications Inconel and aluminum are used. The bellows may have different shapes like U-shaped, semi-toroidal, toroidal, S-shaped, flat, stepped, single sweep, and nested ripple. For designing new bellows basic parameters and those effects must be taken into considerations such as, vibration effect, joints of 6bellows, thermal stresses, flow analysis, fatigue life, selection of materials and shapes etc. Bellows are designed as per the Standards of Expansion Joint Manufactures Association, EJMA [2]. Shaikh, et al. [3] had investigated the failure of an AM350 steel bellows. For that purpose these bellows were used in the controlled rod drive mechanism of the fast breeder test reactor and an experimental work had conducted. Broman et al. [4] recommended I-DEAS software for the simulation of the metal expansion bellows. They proposed that the method will work in any software in which some of the parameters can be set by the user to optimize with respect to overall design parameters. Li [5] had found the effect of the stresses of elliptic degree of $\Omega$-shaped bellows with ideal and elliptic toroids under internal pressure or deflection, and evaluated the state of stress distribution. The designed stress result of $\Omega$-shaped bellows shows that the elliptic degree of $\Omega$-shaped toroid affects the magnitude of the induced stress and axial deflection-induced stress. Broman et al. [4] have determined dynamic characteristics of bellows by manipulating certain parameters of the beam finite elements, Jakubauskas and Werner [6] have considered the transverse vibrations of fluid-filled double-bellows expansion joints. Jha, et al. [7] have investigated the stress corrosion cracking of stainless steel bellows of satellite launch vehicle propellant tank assembly. Zhu et al. [8] have investigated the effect of environmental medium on fatigue life for U-shaped bellows expansion joints. Gawande et al.[9] have carried out extensive analytical and numerical study to calculate the different characteristics of stresses due to internal pressure 
Numerical and Analytical Investigation on the Effect of Dynamic Characteristics of Metal ..

varying from $1 \mathrm{MPa}$ to $2 \mathrm{MPa}$ in U-shaped bellows. Finite element analysis by using ANSYS 14 is performed to find characteristics of U-shaped metal expansion bellows. Gawande et al. [1] have developed the mathematical model for axial natural frequency of bellows, He has performed the numerical and modal analysis for natural frequency of axial vibration of metal expansion bellows and compare the analytical results with experimental results.

From the literature survey, it is seen that number of researchers have worked on study and applications of different types of bellows under various working conditions, their comparison, manufacturing processes and few are working on fatigue life enhancement [9]. But investigations on need for selection of proper material of bellow for given application, their proper design, stresses induced, fatigue life analysis, prediction of failure, investigations on various characteristics of different bellows and vibration effect is essential. As per industrial survey, there is probability of failure of bellows are due to flow induced vibrations. Hence detailed investigations of the effect of flow induced vibration on dynamic characteristic of metal expansion bellows are necessary. In current scenario researchers are work on enhancement of life of bellows. If reduction in bellows failure possibilities due to vibration is executed then there is ultimate chance to enhance the life of bellow.

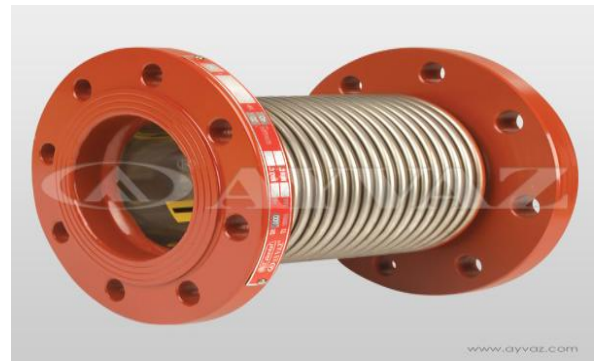

Fig.1 Metal Expansion Bellows

\section{Problem Formulation And Objective Of Research}

As per industrial survey it is seen that bellows are most important element in heat expansion joint. It has the function to absorb regular and irregular expansion and contraction in the system. As the bellows performed in extreme working conditions, there are possibilities of bellows failure due to high stresses, vibration, fatigue etc. As per discussion with experts working in the same field, it is observed that concept of the study in this papers needs detailed understanding of vibration effects and natural frequency of vibration. The work in this paper is based on vibration effect and investigation of numerical and modal analysis of axial natural frequency of vibration. Hence this work focuses on selection of materials of bellows for the given application, their proper design, and determination of effect of vibration on dynamic characteristics of metal expansion bellows. In this research work the basic parameters taken into consideration are the flow induced vibration and the natural frequency of vibration.

\section{Basic Terminology}

The basic terminologies as per the EJMA standard, the following terms has to be considered while designing new bellows.

$p=$ Convolution pitch

$h=$ Convolution height

$\mathrm{D}=\mathrm{ID}$ of cylindrical tangent and bellows convolutions

$n_{t}=$ No. of bellows of ply thickness $\mathrm{t}$
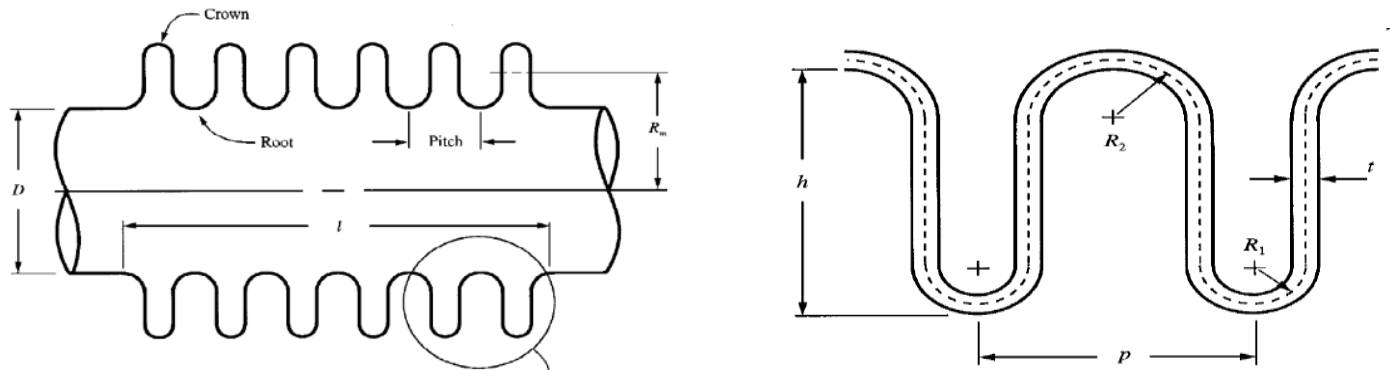

Fig.2 Bellows Geometry 
$t=$ Bellows tangent reinforcing collar material thickness

$\mathrm{L}=$ convoluted length

$\mathrm{Lc}=$ tangent collar length

$\mathrm{Lt}=$ length

1. Convolution height: The height of the convolutions measured from the outside- preferably with slide gauge.

2. Convolution pitch: The crest to crest distance between the convolutions.

3. Cycle: One complete cycle is based upon moving the bellows from neutral length to position 1, back through the neutral length to position 2 and then back to the neutral length.

4. Design Temperature: The maximum and minimum design, operating and installation temperatures should be accurately stated. In situations where the ambient temperature is expected to vary significantly during pipe line construction, special care in expansion joint positioning may be necessary..

5. Design Pressure: The system design pressure, operating pressure and test pressure should be specified realistically without the addition of arbitrary safety factors, because this practice necessitates greater bellows material thickness to withstand the above stated pressures. For standard metal expansion joints the PN (nominal pressure) factor can be defined as the allowed positive operating pressure at room temperature.

6. Design Allowable stress: This is the allowable stress for the bellows material at the bellows design temperature.

7. Modulus of elasticity at Design temperature: This is the modulus of elasticity of the bellow material at the design temperature which is used to calculate spring rate and columns squirm pressure.

8. Modulus of elasticity at ambient temperature: The room temperature modulus of elasticity is used to calculate the deflection stresses.

\section{Mathematical Model For Natural Frequency Of Bellows}

In this work bellow is considered as a long continuous rod or a long pipe having an elemental mass ' $\mathrm{m}$ ' and elemental stiffness 'Ks'. According to Timoshenko beam theory a general solution for the natural frequency is determined. Further bellows with two end conditions are considered in this work, first one is the bellows with one end fixed and other free, second on is bellow with both end fixed.

Consider a beam or a straight pipe of length ' $L$ ' of a constant cross sectional area 'A' as shown in the Fig.4. as per Gawande et al.[1]. Now consider an elemental length $d x$ at a distance ' $x$ ' from one end of the pipe as shown in the Fig.4.1. The axial load acted at a distance $(\mathrm{x}+\mathrm{dx})$ in the opposite direction to ' $\mathrm{P}$ ' is

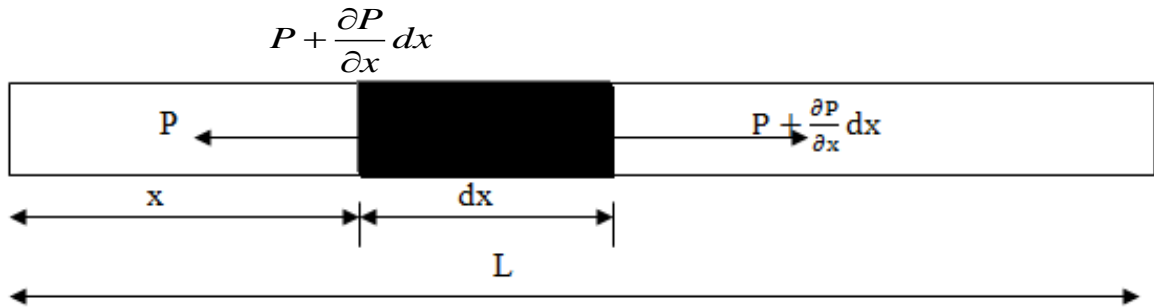

Fig.3 Bellows as a Longitudinal Beam [1]

$\therefore$ The Axial strain in rod; $\quad u=\frac{P L}{A E}$

$\therefore$ The axial strain at the elemental length; $\quad \partial u=\frac{P d x}{A E}$

But;

$$
\begin{aligned}
& P=A E \frac{\partial u}{\partial x} \\
& \frac{\partial P}{\partial x}=A E \frac{\partial^{2} u}{\partial x^{2}}
\end{aligned}
$$

The differential equation to express the axial vibration for the straight pipe can be given by, [5]

$$
\frac{\partial^{2} u}{\partial t^{2}}=a^{2} \frac{\partial^{2} u}{\partial x^{2}}
$$

Where $\mathrm{u}$ is the axial displacement of the pipe (mm), $\mathrm{T}$ is the time (s), $a=\sqrt{E g / v}, E$ is the elastic modulus of the pipe material (MPa), $g$ is the gravitational acceleration $(9806.65 \mathrm{~mm} \mathrm{~s}-\mathrm{E})$ and $\mathrm{v}$ is the weight per unit volume of the pipe material ( $\mathrm{N} \mathrm{mm-3).} \mathrm{[5]}$ 
The solution of the above differential equation is; [1]

$$
\begin{aligned}
& u(x, t)=X(x) \times T(t) \\
& \boldsymbol{u}=\boldsymbol{X} \times \boldsymbol{T} \\
& X=A^{\prime} \sin \left(\frac{\omega}{a}\right) x+B^{\prime} \cos \left(\frac{\omega}{a}\right) x \\
& T=C^{\prime} \sin \omega t+D^{\prime} \cos \omega t
\end{aligned}
$$

Substituting these equations in equation (2)

$$
u=\left[A^{\prime} \sin \left(\frac{\omega}{a}\right) x+B^{\prime} \cos \left(\frac{\omega}{a}\right) x\right]\left[C^{\prime} \sin \omega t+D^{\prime} \cos \omega t\right]
$$

The general solution for the differential equation is;

$$
u(x, t)=\sum_{i=1}^{\infty}\left[A_{i} \sin \left(\frac{\omega}{a}\right) x+B_{i} \cos \left(\frac{\omega}{a}\right) x\right]\left[C_{i} \sin \omega t+D_{i} \cos \omega t\right] \ldots
$$

Assuming the boundary condition as;

One end of the pipe is fixed i.e. $\mathrm{x}=0$ and displacement $\mathrm{u}(0, \mathrm{t})=0$

Applying boundary condition 1 in equation (9) we get;

$$
\begin{aligned}
& u(0, t)=\left[0+B_{i}\right]\left[C_{i} \sin \omega t+D_{i} \cos \omega t\right]=0 \\
& \Rightarrow B_{i}\left[C_{i} \sin \omega t+D_{i} \cos \omega t\right]=0 \\
& {\left[C_{i} \sin \omega t+D_{i} \cos \omega t\right] \neq 0}
\end{aligned}
$$

Here,

$$
\therefore B_{i}=\mathrm{O}
$$

Substituting value in equation (5) we get;

$$
u=\sum_{i=1}^{\infty}\left[A_{i} \sin \left(\frac{\omega}{a}\right) x\right]\left[C_{i} \sin \omega t+D_{i} \cos \omega t\right]
$$

Now to develop a mathematical model of bellows, it is assumed that a straight pipe with continuously and uniformly distributed mass is fixed at its bottom. A weight W0 is attached to its top, and the weight is connected with a spring. Now from the Fig.4.2 the equilibrium equation according to D'Alembertz principle can be written as; [5]

$$
A E \frac{\partial u}{\partial x}+\frac{W_{0}}{g} \frac{\partial^{2} u}{\partial T^{2}}+K_{s} u=0 .
$$

The general solution for the differential equation is; [1]

$A E \times \frac{\omega}{a} A^{\prime} \cos \left(\frac{\omega}{a}\right) \times\left[C^{\prime} \sin \omega t+D^{\prime} \cos \omega t\right]-\frac{W_{0}}{g} A^{\prime} \sin \left(\frac{\omega}{a}\right) \times\left[C^{\prime} \omega \sin \omega T+D^{\prime} \omega \cos \omega T\right]+K_{s}\left[A^{\prime} \sin \left(\frac{\omega}{a}\right) x\right]\left[C^{\prime} \sin \omega t+D^{\prime} \cos \omega t\right]=0$

Further simplification we get;

$$
A E \frac{\omega_{i}}{a} \cos \frac{\omega_{i}}{a} L-\frac{W_{0}}{g} \omega_{i}^{2} \sin \frac{\omega_{i}}{a} L+K_{s} \sin \frac{\omega_{i}}{a} L=0 .
$$

The term L/a can be further simplified as;

$$
\frac{L}{a}=\sqrt{\frac{L A v}{A E g / L}}=\sqrt{\frac{G / g}{P / L \frac{\partial u}{\partial x}}}=\sqrt{\frac{G}{g K_{n}}}
$$

Where $\mathrm{G}$ is the weight of the pipe in N, P is the applied axial force in N, and $K_{n}$ is the Axial spring rate of the pipe in $\mathrm{N} / \mathrm{mm}$.

$$
E=\frac{\left(\frac{Q}{A}\right)}{\left(\frac{\partial u}{\partial x}\right)} \quad \text { and } \quad K_{n}=\frac{Q}{L\left(\frac{\partial u}{\partial x}\right)}
$$

Substituting the value of equation (9) in equation (8) we get; 

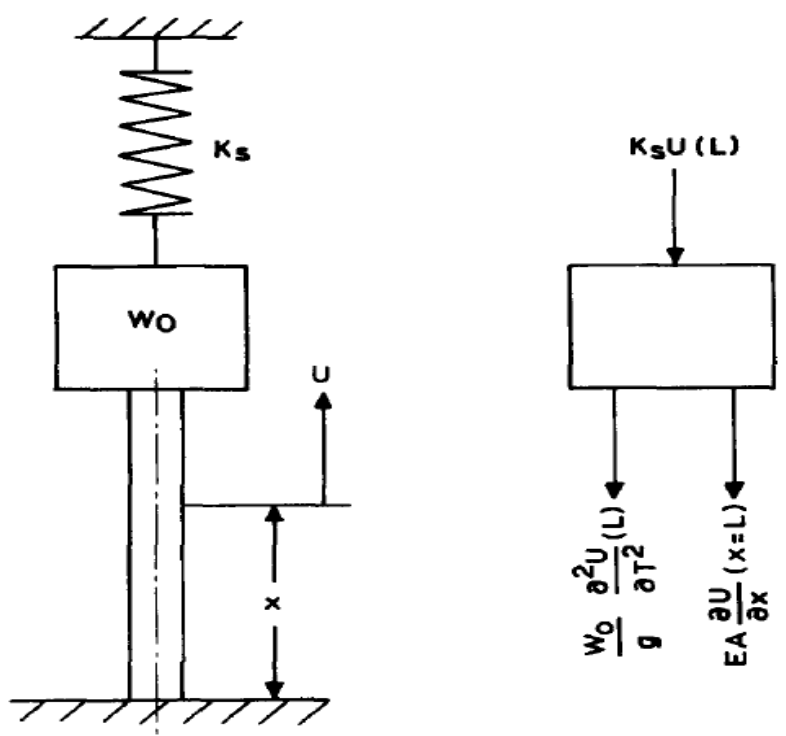

Fig.4 Free body diagram (FBD) of bellows [5]

$A E \frac{\omega_{i}}{a} \cos \omega_{i} \sqrt{\frac{G}{g K_{n}}}-\frac{W_{0}}{g} \omega_{i}^{2} \sin \omega_{i} \sqrt{\frac{G}{g K_{n}}}+K_{s} \sin \omega_{i} \sqrt{\frac{G}{g K_{n}}}=0$.

The axial natural frequencies of the bellows can be calculated by using the above equation with different end conditions.

\subsection{Condition 1: One end of the bellows is fixed and other end free} i.e. $W_{0}=0$ and $K_{s}=0$;

Substituting the values in equation (10) we get;

$$
\begin{aligned}
& \cos \omega_{i} \sqrt{\frac{G}{g K_{n}}}=0 \\
\Rightarrow & \omega_{i} \sqrt{\frac{G}{g K_{n}}}=\frac{(i-1) \pi}{2} \\
\Rightarrow & \omega_{i}=\frac{(i-1) \pi}{2} \sqrt{\frac{g K_{n}}{G}}
\end{aligned}
$$

Where ' $\mathrm{i}$ ' is known as the order number of natural frequency, $\mathrm{i}=1,2,3,4 \ldots$.

$$
\begin{aligned}
\therefore f_{i} & =\frac{\omega_{i}}{2 \pi} \\
\Rightarrow f_{i} & =\frac{\frac{(i-1)}{2} \sqrt{\frac{g K_{n}}{G}}}{2 \pi}
\end{aligned}
$$

Substituting the value of $g=9806.65 \mathrm{~mm} / \mathrm{s} 2$ the frequency equation is;

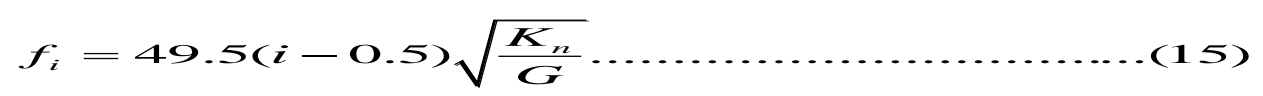

\subsection{Condition 2: Both end of the bellows are fixed}

i.e. $W_{0}=0$ and $K_{s}=\infty$;

Substituting the values in equation (10) we get;

$$
\begin{aligned}
& \sin \omega_{i} \sqrt{\frac{G}{g K_{n}}}=0 \\
& \Rightarrow \omega_{i} \sqrt{\frac{G}{g K_{n}}}=\frac{i \pi}{2}
\end{aligned}
$$




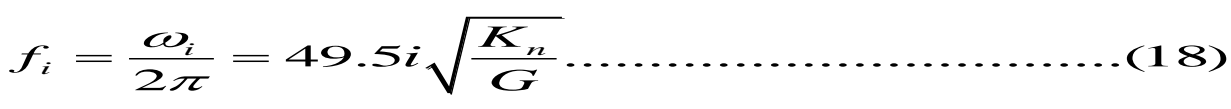

\section{Numerical Analysis}

MATLAB software is selected to perform numerical analysis of metal expansion bellows. In accordance with the mathematical model MATLAB codes are generated in MATLAB editor window. The program generation is done in the MATLAB editor window. First the material properties of the bellows like modulus of elasticity, density, specific weight and poisson's ratio etc., are assign. Then the dimensions of bellows like the outer diameter, number of convolutions, pitch and thickness are assigning. After that the final equations obtained from the mathematical model with different condition are provided and finally program run is executed, which lastly plots the required axial natural frequencies of the bellows. For the simulation SA-240 321 material is selected. In this present analysis, a U-shaped bellow is selected as shown in Fig.1. The value of axial spring rate $(\mathrm{Kn})$ for bellow is calculated according to the EJMA standard equations. The bellows having geometrical parameters such as;

Table 5.1 Bellows Geometrical Parameters

\begin{tabular}{|c|c|c|}
\hline Sr. No. & Bellows Geometrical Parameters & Value \\
\hline 1 & Outside diameter & $147 \mathrm{~mm}$ \\
\hline 2 & Thickness & $0.9 \mathrm{~mm}$ \\
\hline 3 & Convolution Pitch & $8 \mathrm{~mm}$ \\
\hline 4 & Convolution Height & $8 \mathrm{~mm}$ \\
\hline
\end{tabular}

Using equation (9), (12) and (13) natural frequencies are obtained according to the boundary conditions. Table 5.1, 5.2 and 5.3 shows the detail geometrical, material specifications and chemical composition of bellows used in this work.

Table 5.2 Specifications of Bellows

\begin{tabular}{|c|c|c|}
\hline Sr. No. & Parameter & Specifications \\
\hline 1 & Expansion joint material & SA-240 321 \\
\hline 2 & Modulus of elasticity & $195000 \mathrm{~N} / \mathrm{mm} 2$ \\
\hline 3 & Bellows yield stress & $157.39 \mathrm{~N} / \mathrm{mm} 2$ \\
\hline 4 & Poisson's ratio & 0.3 \\
\hline 5 & Bellow material condition & Formed \\
\hline 6 & Bellow type & U-shaped \\
\hline 7 & Convolution depth & $8 \mathrm{~mm}$ \\
\hline 8 & Convolution pitch & $8 \mathrm{~mm}$ \\
\hline 9 & Total number of convolution & 10 \\
\hline 10 & Nominal thickness of ply & 0.3 \\
\hline 11 & Total number of plies & 3 \\
\hline 12 & End tangent length & 13 \\
\hline
\end{tabular}

Table 5.3 Chemical Composition of Bellows

\begin{tabular}{|c|c|c|c|c|c|c|}
\hline $\mathrm{C}$ & $\mathrm{Cr}$ & $\mathrm{Mn}$ & $\mathrm{Ni}$ & $\mathrm{P}$ & $\mathrm{S}$ & $\mathrm{Si}$ \\
\hline Max. & & Max. & & Max. & Max. & Max. \\
\hline 0.0008 & $17 \%-20 \%$ & 0.02 & $9 \%-13 \%$ & 0.0004 & 0.0003 & 0.0075 \\
\hline
\end{tabular}

\subsection{Condition1: Bellows with one end fixed and other end free}

Table 5.4 and Fig. 5.2 (a) and (b) shows the natural frequencies of bellow with one end fixed and other end free condition for 6 and 7 convolution bellows respectively. A series of MATLAB programs is executed, according to the mathematical relations from equation (6), (9) and (10) and varying the parameter ' $n$ ' (numbers of convolutions), natural frequencies are found. For this boundary condition the range of frequencies lies from $474.58-2372.94 \mathrm{~Hz}$ for the number of convolutions $\mathrm{n}=6$ and $503.21-2333.07 \mathrm{~Hz}$ for the number of convolutions $\mathrm{n}=7$. 
Numerical and Analytical Investigation on the Effect of Dynamic Characteristics of Metal ..

Table 5.4 Natural Frequencies of bellows with one end fixed and other end free condition

\begin{tabular}{|c|c|c|}
\hline Sr. No & $\mathrm{n}=6$ & $\mathrm{n}=7$ \\
\hline 1 & 474.58 & 503.21 \\
\hline 2 & 580.05 & 686.19 \\
\hline 3 & 685.51 & 960.67 \\
\hline 4 & 896.44 & 1052.17 \\
\hline 5 & 1001.90 & 1143.66 \\
\hline 6 & 1107.37 & 1235.15 \\
\hline 7 & 1212.83 & 1326.65 \\
\hline 8 & 1318.30 & 1509.63 \\
\hline 9 & 1423.76 & 1784.11 \\
\hline 10 & 1529.22 & 1875.61 \\
\hline 11 & 1634.69 & 1967.10 \\
\hline 12 & 2056.55 & 2058.59 \\
\hline 13 & 2162.01 & 2150.09 \\
\hline 14 & 2267.47 & 2241.58 \\
\hline 15 & 2372.94 & 2333.07 \\
\hline
\end{tabular}

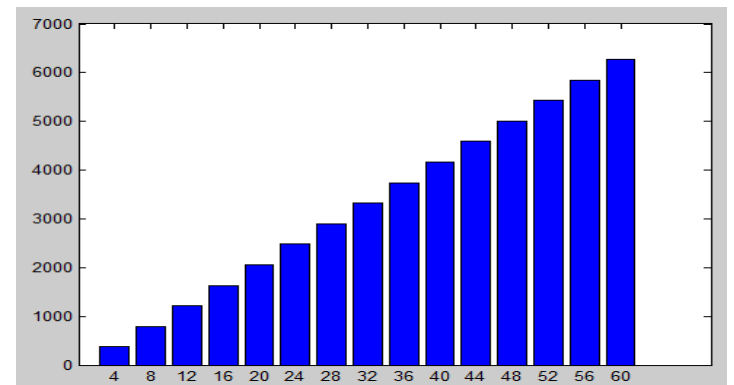

(a)

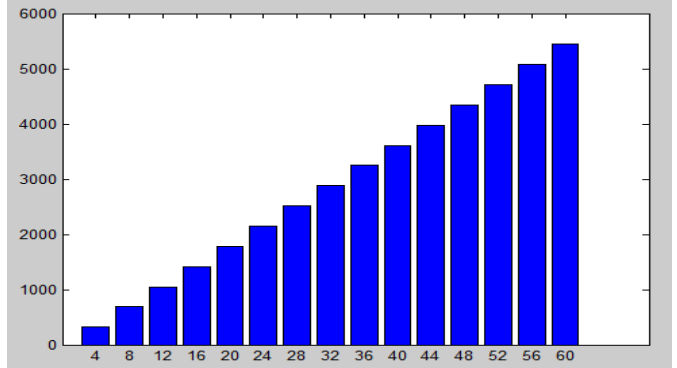

(b)

Fig. 5.2 Natural frequency of bellow with 6 and 7 convolutions for bellows with one end fixed and other end free condition

Table 5.5 and Fig. 5.3 (a) and (b) shows the natural frequencies of bellow with both end fixed condition for 6 and 7convolution bellows respectively. A series of MATLAB programs is executed, according to the mathematical relations from equation (6), (9) and (10) and varying the parameter ' $n$ ' (numbers of convolutions), natural frequencies are found. For this boundary condition the range of frequencies lies from 1792.89-4324.02 $\mathrm{Hz}$ for the number of convolutions $\mathrm{n}=6$ and $1829.86-4025.70 \mathrm{~Hz}$ for the number of convolutions $\mathrm{n}=7$

Table 5.5 Natural Frequencies of bellows with both end fixed condition

\begin{tabular}{|c|c|c|}
\hline Sr. No & $\mathrm{n}=6$ & $\mathrm{n}=7$ \\
\hline 1 & 1792.89 & 1829.86 \\
\hline 2 & 1898.35 & 2012.85 \\
\hline 3 & 2003.81 & 2287.33 \\
\hline 4 & 2109.28 & 2561.81 \\
\hline 5 & 2214.74 & 2653.30 \\
\hline 6 & 2952.99 & 2744.79 \\
\hline 7 & 3058.45 & 2736.29 \\
\hline 8 & 3374.85 & 2927.29 \\
\hline 9 & 3480.31 & 3019.27 \\
\hline 10 & 3691.24 & 3110.77 \\
\hline 11 & 3796.70 & 3476.74 \\
\hline 12 & 3902.17 & 3568.23 \\
\hline 13 & 4007.63 & 3842.71 \\
\hline 14 & 4218.56 & 3934.21 \\
\hline 15 & 4324.02 & 4025.70 \\
\hline
\end{tabular}



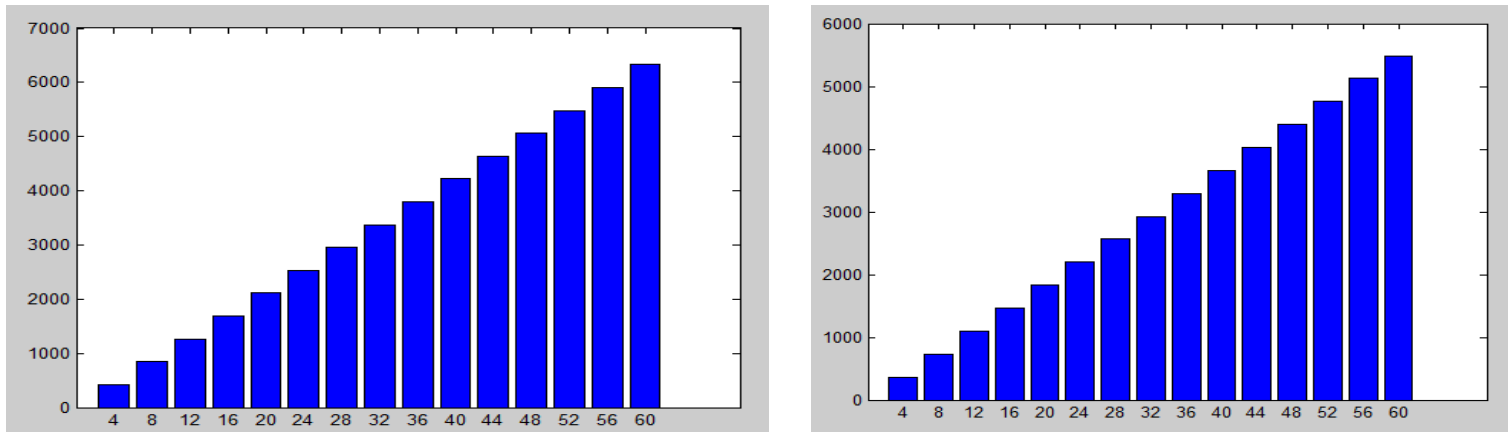

Fig. 5.3 Natural frequency of bellow with 6 and 7 convolutions for bellows with both end fixed condition

\section{Modal Analysis}

Modal analysis is used to determine the vibration characteristics of a structure, namely the natural frequencies and the mode shapes of the structure. The natural frequencies and mode shapes are important parameters in the design of a structure for dynamic loading conditions which determined by the inherent characteristics and the materials of a structure. In order to perform modal analysis, a solid model of metal expansion bellows is generated in NX8 software and then transferred to .iges format. Then the geometry is imported to ANSYS R15.0 Workbench

\subsection{Procedure for Modal analysis}

Numerical simulation is followed by three stages; pre-processing, solution, post-processing as shown in the Fig.5.1. In pre-processing stage modeling, defining material properties like young's modulus, poisson's ratio, density etc. and meshing is done. In this first stage solid model bellows has to create in iges format and imported to the ANSYS workbench and the material properties are provided by using the project and editor window. In this work the mesh generation with a fine meshing is carry out. Second stage involves applying the boundary conditions on the model and generating the solution. In the second stage the bellows with one end fixed and one end free condition and both end fixed condition are used as boundary conditions. And solutions are generated. In post-processing the modal analysis was carried out and results are plotted. In this stage the modal solutions with modal frequencies and mode shapes are generated.

\subsection{Mode shapes of bellows with one end fixed and other end free condition}

Table 6.2 shows the modal frequencies of bellows with one end fixed and one end free condition for 6 and 7 convolution bellows respectively. Figs 6.2 (a) and (b) shows the mode shapes of bellows having maximum deformation $209.29 \mathrm{~mm}$ with frequency $2270.7 \mathrm{~Hz}$ for 6 convolutions and $208.23 \mathrm{~mm}$ with frequency $2287.90 \mathrm{~Hz}$ for 7 convolutions for 6 th mode.

Table 6.2 Modal frequencies of bellow with one end fixed and other end free condition

\begin{tabular}{|c|c|c|}
\hline Mode No & $\mathrm{n}=6$ & $\mathrm{n}=7$ \\
\hline 1 & 1162.8 & 1079.4 \\
\hline 2 & 1165.3 & 1083.6 \\
\hline 3 & 1396.3 & 1184.1 \\
\hline 4 & 1409.8 & 1196.5 \\
\hline 5 & 1587.1 & 1386.5 \\
\hline 6 & 2270.7 & 2287.9 \\
\hline
\end{tabular}

The analysis results are as shown in Fig 6.2 (a) and (b) for 6 and 7 convolution bellows with one end fixed and other end free condition respectively 


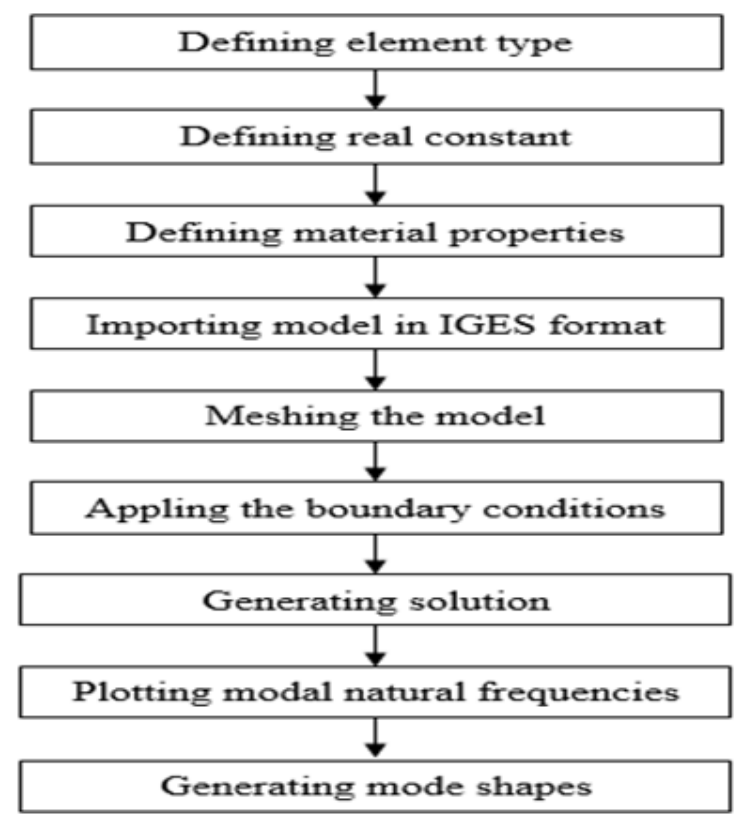

Fig. 6.1 Steps for Modal Analysis

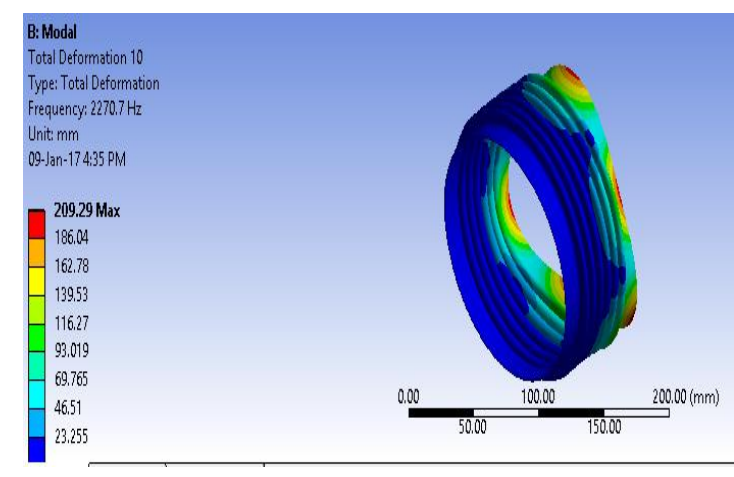

(a)

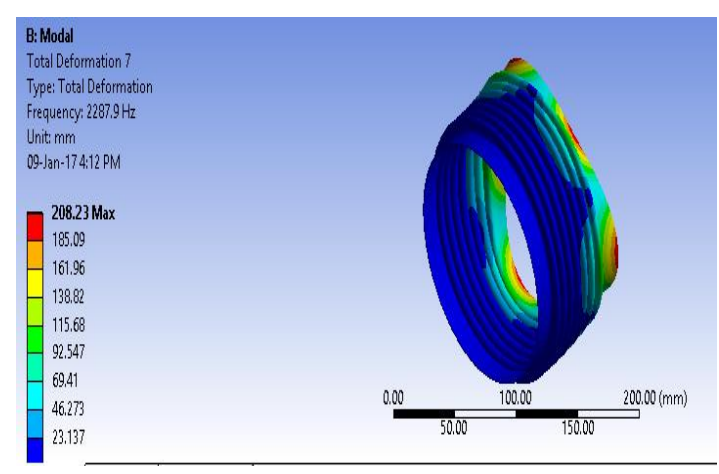

(b)

Fig 6.2 Maximum deformation of bellow with 6 and 7 convolutions for bellows with one end fixed and other end free condition

\subsection{Mode shapes of bellows with both end fixed condition}

Table 6.3 shows the modal frequencies of bellows with both end fixed condition. Figs 6.3 (a) and (b) shows the mode shapes of bellows having maximum deformation $108.74 \mathrm{~mm}$ with frequency $4266.7 \mathrm{~Hz}$ for 6 convolutions and $102.89 \mathrm{~mm}$ with frequency $3928.7 \mathrm{~Hz}$ for 7 convolutions for 6 th mode.

Table 6.3 Modal frequencies of bellow with both end fixed condition

\begin{tabular}{|c|c|c|}
\hline Mode No & $\mathrm{n}=6$ & $\mathrm{n}=7$ \\
\hline 1 & 3312.5 & 2877.5 \\
\hline 2 & 3727.3 & 3183.9 \\
\hline 3 & 3745.2 & 3198.7 \\
\hline 4 & 3809.3 & 3547.7 \\
\hline 5 & 3812.4 & 3549.1 \\
\hline 6 & 4266.7 & 3928.7 \\
\hline
\end{tabular}

The analysis results are as shown in Fig 6.3 (a) and (b) for 6 and 7 convolution bellows with both end fixed condition respectively. 


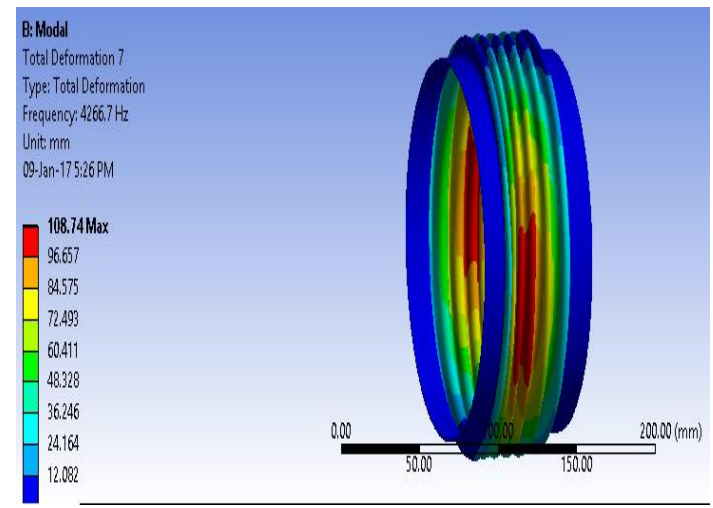

(a)

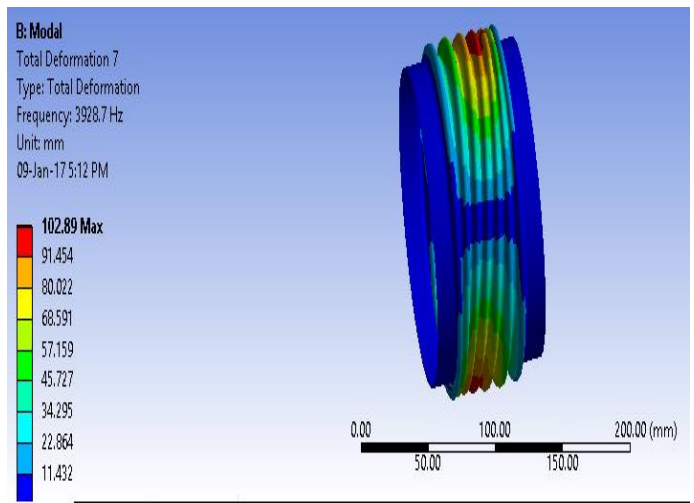

(b)

Fig 6.3 Maximum deformation of bellow with 6 and 7 convolutions for bellows with both end condition

\section{Results And Discussion}

Comparison of results of numerical and modal analysis performed in MATLAB and ANSYS software, for 6 and 7 convolution bellows with one end fixed and other end free condition and with both end fixed condition are tabulated. Table 7.1 and 7.2 shows the axial frequency range for both conditions. Fig 7.1 shows the comparison of frequencies.

Table 7.1 Comparison of results for 6 convolution bellows with one end fixed and other end free condition

\begin{tabular}{|c|c|c|c|c|}
\hline No of Modes & \multicolumn{2}{|c|}{ Frequencies $(\mathrm{Hz})$} & \multicolumn{2}{c|}{ Frequencies $(\mathrm{Hz})$} \\
\hline & \multicolumn{2}{|c|}{ For 6 convolution bellows } & \multicolumn{2}{c|}{ For 7 convolution bellows } \\
\hline & Numerical & Modal & Numerical & Modal \\
\hline 1 & 1001.90 & 1162.8 & 960.67 & 1079.4 \\
\hline 2 & 1107.37 & 1165.3 & 1052.17 & 1083.6 \\
\hline 3 & 1318.30 & 1396.3 & 1143.66 & 1184.1 \\
\hline 4 & 1423.76 & 1409.8 & 1235.15 & 1196.5 \\
\hline 5 & 1529.69 & 1587.1 & 1326.65 & 1386.5 \\
\hline 6 & 2267.47 & 2270.7 & 2241.58 & 2287.9 \\
\hline
\end{tabular}

Table 7.2 Comparison of results for 6 convolution bellows with both end fixed condition

\begin{tabular}{|c|c|c|c|c|}
\hline No of Modes & \multicolumn{2}{|c|}{ Frequencies (Hz) } & \multicolumn{2}{c|}{ Frequencies (Hz) } \\
\hline & \multicolumn{2}{|c|}{ For 6 convolution bellows } & \multicolumn{2}{c|}{ For 7 convolution bellows } \\
\hline & Numerical & Modal & Numerical & Modal \\
\hline 1 & 3374.85 & 3312.5 & 2836.29 & 2877.5 \\
\hline 2 & 3691.24 & 3727.3 & 3110.77 & 3183.9 \\
\hline 3 & 3796.70 & 3745.2 & 3202.26 & 3198.7 \\
\hline 4 & 3902.17 & 3809.3 & 3476.74 & 3547.7 \\
\hline 5 & 4007.63 & 3812.4 & 3568.23 & 3549.1 \\
\hline 6 & 4218.56 & 4266.7 & 3934.21 & 3928.7 \\
\hline
\end{tabular}

Modal analysis is done for safety of bellows and prevention of fatigue failure Fig 7.1 shows the mode shapes of bellows. From observations it is clear that maximum deformation occurs at the convolutions. If shorter piping systems are used in process industries, then the bellows are welded to the ends of pipes. As per research work, natural frequency at bellows with both end fixed condition is high as compare to one end fixed other end free condition. Hence the design engineer has to maintain the flow rate of the fluid to reduce the natural frequency of vibration. 


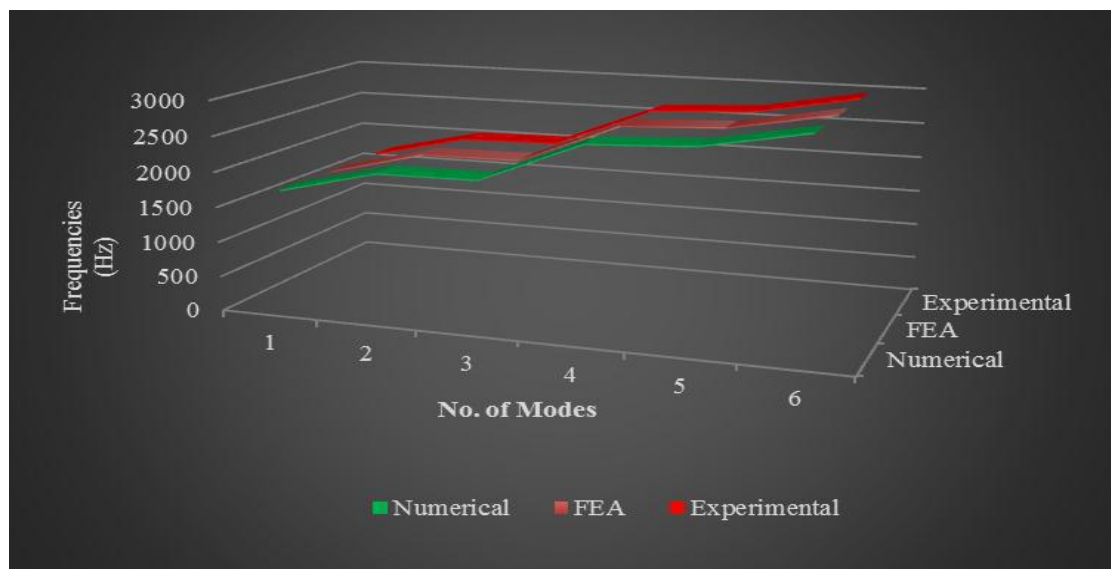

Fig 7.1 Comparison of frequencies

It is concluded that,

\section{Conclusion}

- Natural frequency of vibration decreases with increase in number of convolutions of bellows.

- To maintain the flow rate of fluid, the design engineer has to increase the number of convolutions of bellows.

- Result shows that there is a close match between numerical and modal analysis of 6 and 7 convolution bellows with considered boundary conditions.

- The approach proposed in this research work for finding natural frequency of vibration is correct and is suitable to use for other applications.

- The axial natural frequency of $6^{\text {th }}$ mode for bellows with both end fixed is higher than the bellows with one end fixed and other end free.

- To avoid the failure of bellows and to enhance the fatigue life of bellows, the approach proposed in this research work is significant.

[1] S.H. Gawande and N.D.Pagar, "A Combined Numerical and Experimental Investigation on the Effect of Dynamic Characteristics of Metal Expansion Bellows", Hindawi Publishing Corporation International Journal of Metals Volume 2015, Article ID 957925.

[2] EJMA, Standards of Expansion Joint Manufacturers Association, $9^{\text {th }}$ edition, New York, 2008.

[3] H. Shaikh, G. George, and H. S. Khatak, "Failure analysis of an AM 350 steel bellows", Engineering Failure Analysis, vol. 8, no. 6, pp.571-576, 2001.

[4] G. I. Broman, A. P. Jonsson, and M. P. Hermann, "Determining dynamic characteristics of bellows by manipulated beam finite elements of commercial software", International Journal of Pressure Vessels and Piping, vol .77,no.8, pp.445-453, 2000.

[5] T. Li, "Effect of the elliptic degree of $\Omega$-shaped bellows toroid on its stresses", International Journal of Pressure Vessels and Piping,vol. 75, no. 13, pp.951-954,1998.

[6] V. Jakubauskas, D. S. Werner, "Transverse natural frequencies and flow induced vibrations of double bellows expansion joints", Journal of Fluids\& Structures, vol.13, no.4, pp.461-479, 1999.

[7] A. K. Jha, V. Diwakar, K.Sreekumar, "Stress corrosion cracking of stainless steel bellows of satellite launch vehicle propellant tank assembly", Journal Engineering Failure Analysis, vol.10, no.6, pp.699-709, 2003.

[8] Y.Z. Zhu, H,F.Wang, and Z.F.Sang, The effect of environmental medium on fatigue life for u-shaped bellows expansion joints, International Journal of Fatigue, vol. 28, no.1, pp.1-5, 2005.

[9] S.H. Gawande, N.D.Pagar, V.B.Wagh, and A.A. Keste, Numerical Investigations on Characteristics of Stresses in U Shaped Metal Expansion Bellows. International Journal of Metals, 2015, 1-9, (2015).

\section{APPENDICES}

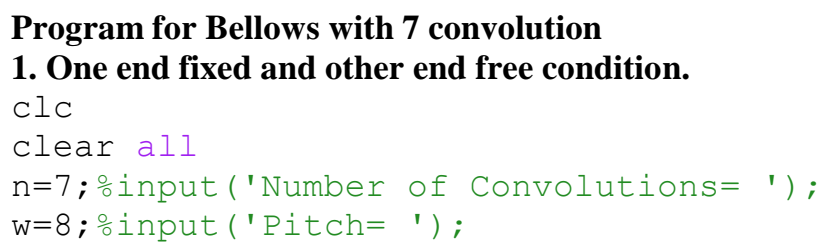




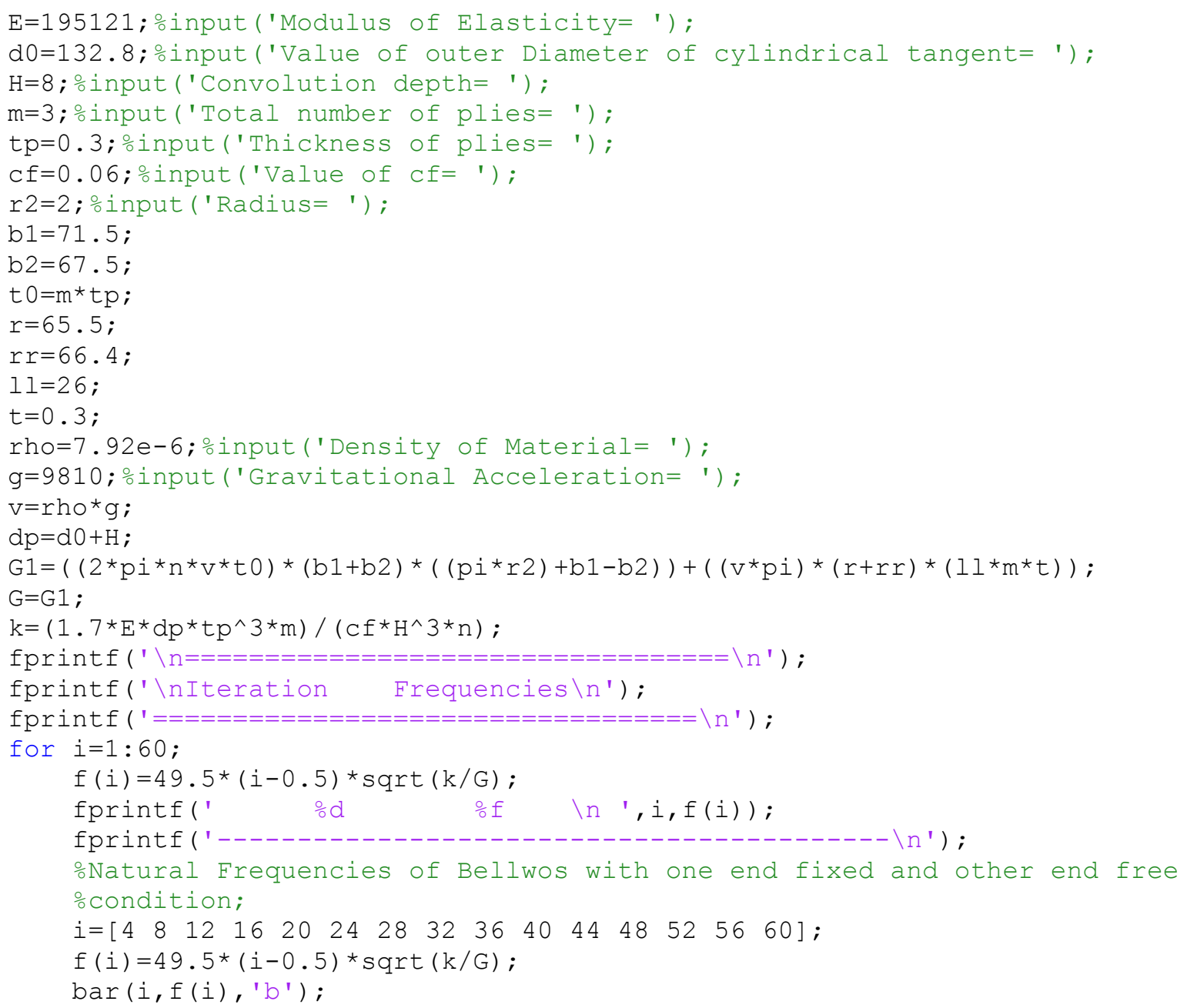

end

\section{Both end fixed condition.}

$\mathrm{ClC}$

clear all

$\mathrm{n}=7$; 을

$\mathrm{w}=8$; 을 $($ 'Pitch $=$ ') ;

$\mathrm{E}=195121$; 을 ('Modulus of Elasticity= ') ;

d0=132.8; \%input ('Value of outer Diameter of cylindrical tangent= '); $\mathrm{H}=8$; $\%$ input ('Convolution depth= ') ;

$\mathrm{m}=3$; input ('Total number of plies= ');

tp $=0.3$; \%input ('Thickness of plies = ');

cf $=0.06$; \%input ('Value of $\mathrm{cf}=$ ') );

$r 2=2$; $\circ$ input ( 'Radius= ' );

$\mathrm{b} 1=71.5$

$\mathrm{b} 2=67.5$

t $0=m * t p ;$

$r=65.5$;

$r r=66.4 ;$

$11=26$;

$\mathrm{t}=0.3$;

rho=7.92e-6; 으ut ('Density of Material= ') ;

g=9810; ㅇput ('Gravitational Acceleration= ') ;

$\mathrm{v}=\mathrm{rho}{ }^{*} \mathrm{~g}$;

$\mathrm{dp}=\mathrm{d} 0+\mathrm{H}$ 


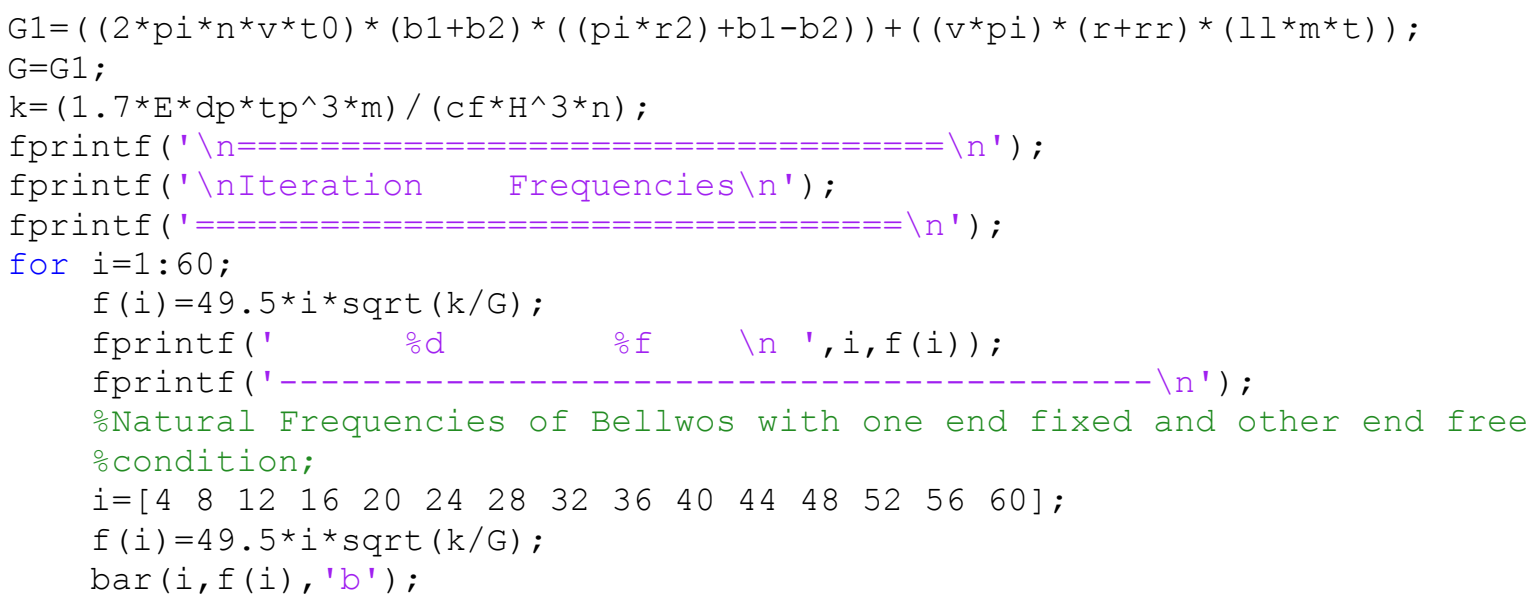

end 